Supporting Information

\title{
Crystallisation From Volatile Deep Eutectic Solvents
}

Jason Potticary, Charlie Hall1,2, Victoria Hamilton ${ }^{1,3}$, James F. McCabe ${ }^{4}$, Simon R. $\mathrm{Hall}^{1^{*}}$

*Correspondence to: simon.hall@bristol.ac.uk

\begin{tabular}{|c|c|c|c|c|}
\hline $\begin{array}{l}\text { Compound } \\
\left.\text { (m.p. }\left({ }^{\circ} \mathrm{C}\right)\right)\end{array}$ & $\begin{array}{c}\text { Designation in } \\
\text { this study (Figure } \\
\text { S1) }\end{array}$ & $\begin{array}{c}\text { VC } \\
\left.\text { (m.p. }\left({ }^{\circ} \mathrm{C}\right)\right)\end{array}$ & $\begin{array}{l}\text { Lowest } \\
\text { VODES } \\
\text { m.p. / } \mathrm{T}_{\mathrm{g}} \\
\left({ }^{\circ} \mathrm{C}\right)\end{array}$ & $\begin{array}{l}\text { Lowest } \\
\text { m.p. ratio } \\
\text { (VC:API) }\end{array}$ \\
\hline Phenol (40.5) & $\mathrm{n} / \mathrm{a}(1)$ & $\begin{array}{c}- \\
\text { Phenol }\end{array}$ & - & - \\
\hline Paracetamol (169) & PAP (2) & $\begin{array}{l}\text { (40.5) } \\
\text { Phenol }\end{array}$ & $<-70$ & $7: 1-10: 1$ \\
\hline Metacetamol (149) & MAP (3) & (40.5) & -58 & $4: 1$ \\
\hline Orthocetamol (210) & OAP (4) & $\mathrm{n} / \mathrm{a}$ & $\mathrm{n} / \mathrm{a}$ & $\mathrm{n} / \mathrm{a}$ \\
\hline Benzamide (130) & $\mathrm{n} / \mathrm{a}(5)$ & $\begin{array}{l}\text { Phenol } \\
\text { (40.5) }\end{array}$ & -19 & $10: 1$ \\
\hline $\begin{array}{l}\text { 2-methoxybenzamide } \\
\text { (128) }\end{array}$ & $2 \mathrm{MB}(6)$ & $\begin{array}{l}\text { Phenol } \\
\text { (40.5) }\end{array}$ & $<-70$ & $4: 1$ \\
\hline $\begin{array}{l}\text { 2-ethoxybenzamide } \\
\text { (134) }\end{array}$ & 2EB (7) & $\begin{array}{l}\text { Phenol } \\
\text { (40.5) }\end{array}$ & $<-70$ & $4: 1$ \\
\hline
\end{tabular}




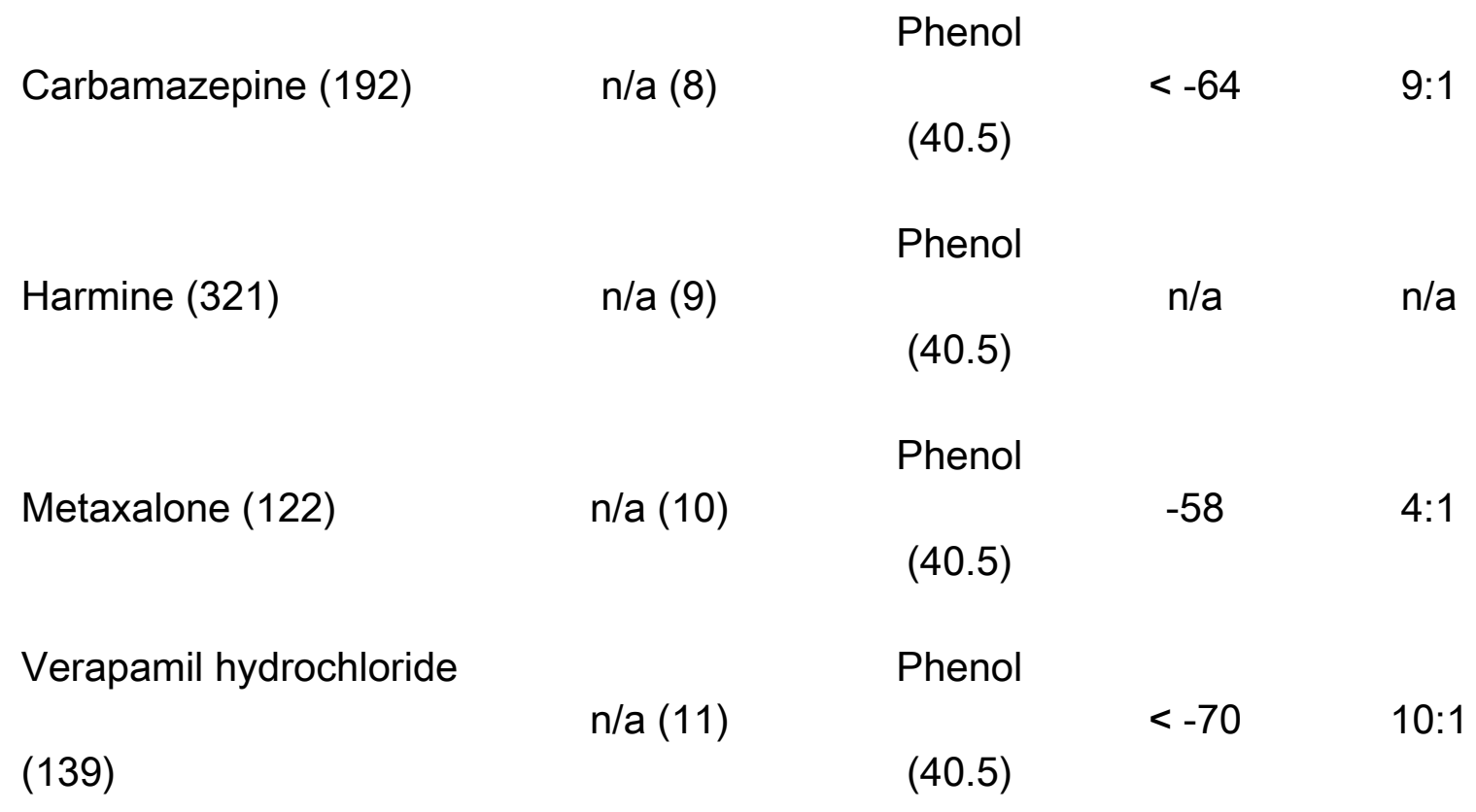

Table S1. Summary of melting points of the compounds considered in this study and that of their respective VODES. 
<smiles>CC(=O)Nc1ccc(O)cc1NC(C)=O</smiles><smiles>CCOc1ccccc1C(N)=O</smiles><smiles>NC(=O)N1c2ccccc2C=Cc2ccccc21</smiles><smiles>COc1ccc2c(c1)[nH]c1c(C)nccc12</smiles><smiles>Cc1cc(C)cc(OCC2CNC(=O)O2)c1</smiles>

10<smiles>C/C=C(\C)C(C#N)(CCCN(C)CCc1ccc(OC)c(OC)c1)C(C)C</smiles>

Figure S1. The compounds considered in this study. Numbers are identified in table 


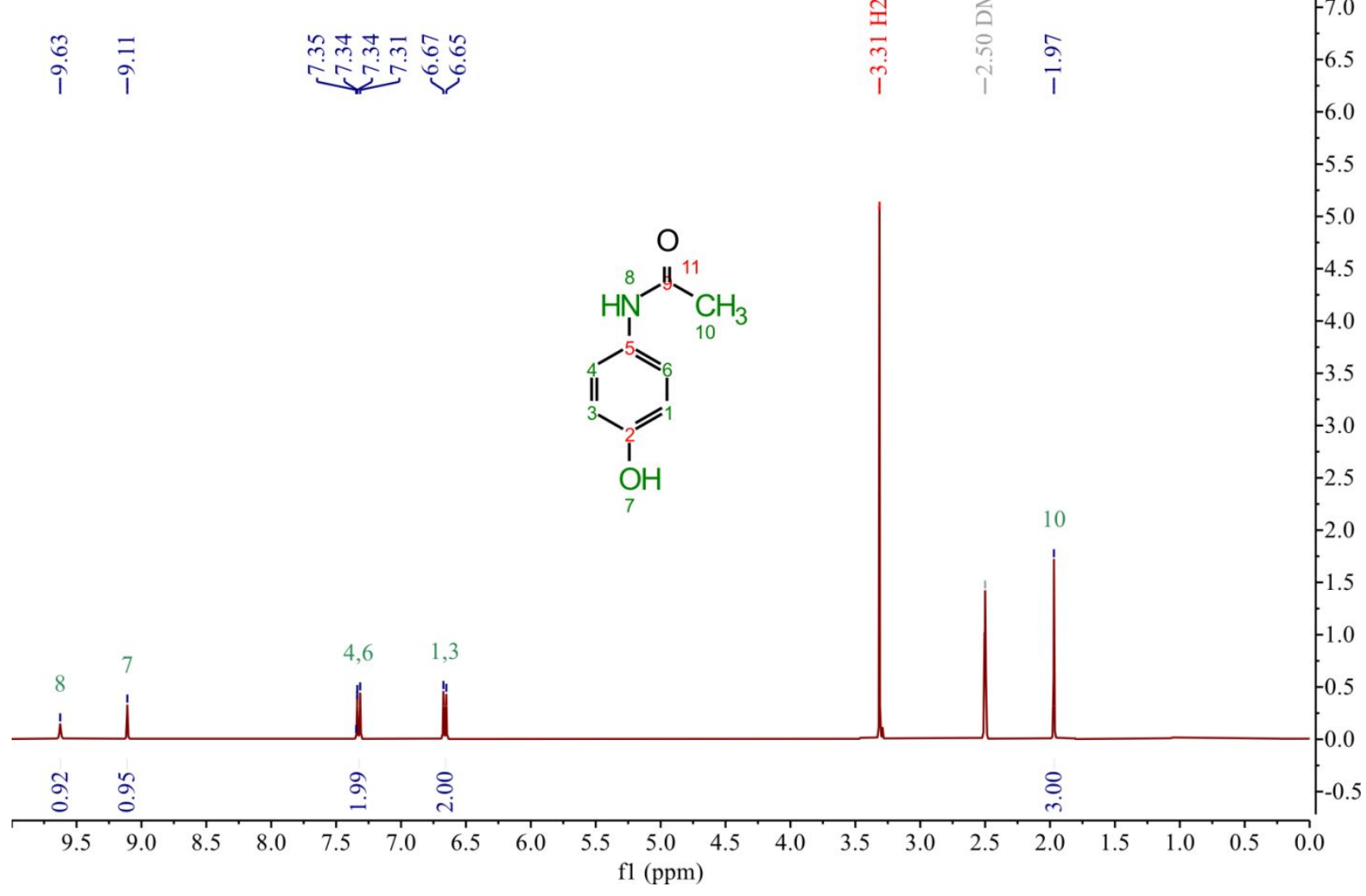

Figure S2. ${ }^{1} \mathrm{H}$ NMR of paracetamol after crystallisation from a 6:1 VODES with phenol. All peaks can be assigned to paracetamol and are correctly integrated. There is no proton peak from phenol present (c.a. $9.28 \mathrm{ppm}$ in $\mathrm{DMSO}-\mathrm{d}_{6}$ ), indicating an absence of residual phenol in the product. 


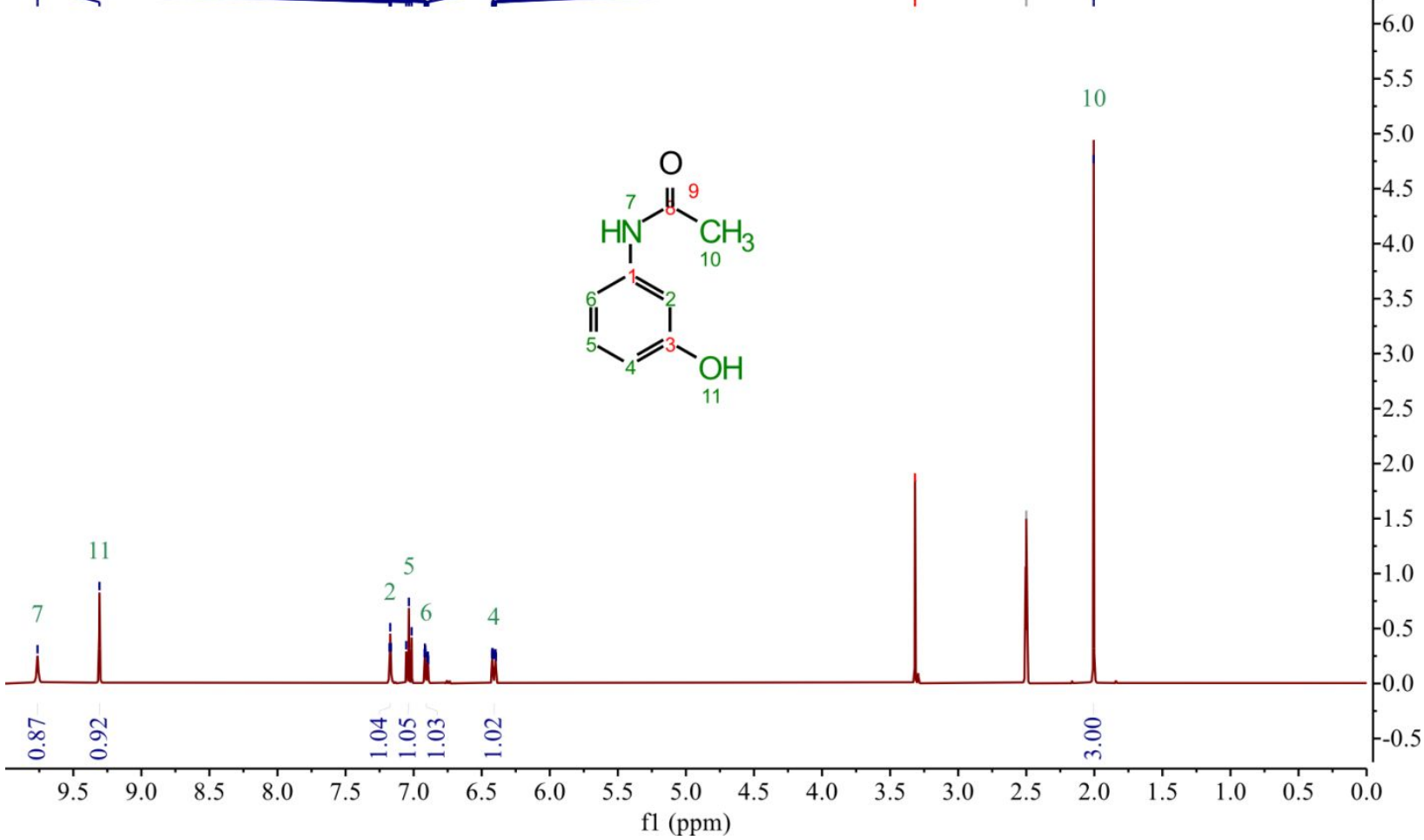

Figure S3. ${ }^{1} \mathrm{H}$ NMR of metacetamol after crystallisation from a 6:1 VODES with phenol. All peaks can be assigned to metacetamol and are correctly integrated. There is no proton peak from phenol present (c.a. 9.28 ppm in DMSO- $d_{6}$ ), indicating an absence of residual phenol in the product. 


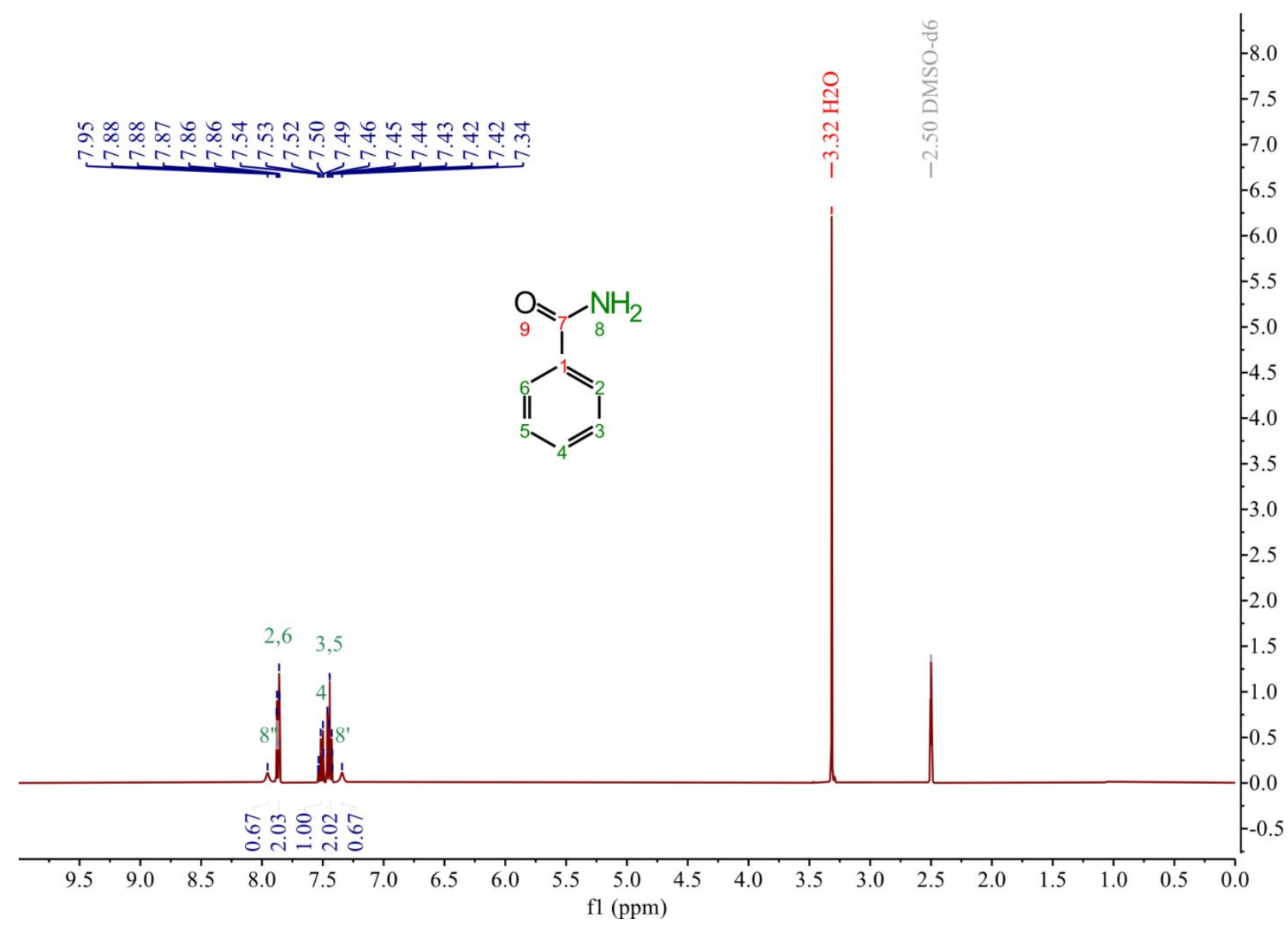

Figure S4. ${ }^{1} \mathrm{H}$ NMR of benzamide after crystallisation from a 6:1 VODES with phenol. All peaks can be assigned to benzamide and are correctly integrated. There is no proton peak from phenol present (c.a. 9.28 ppm in DMSO- $d_{6}$ ), indicating an absence of residual phenol in the product. 


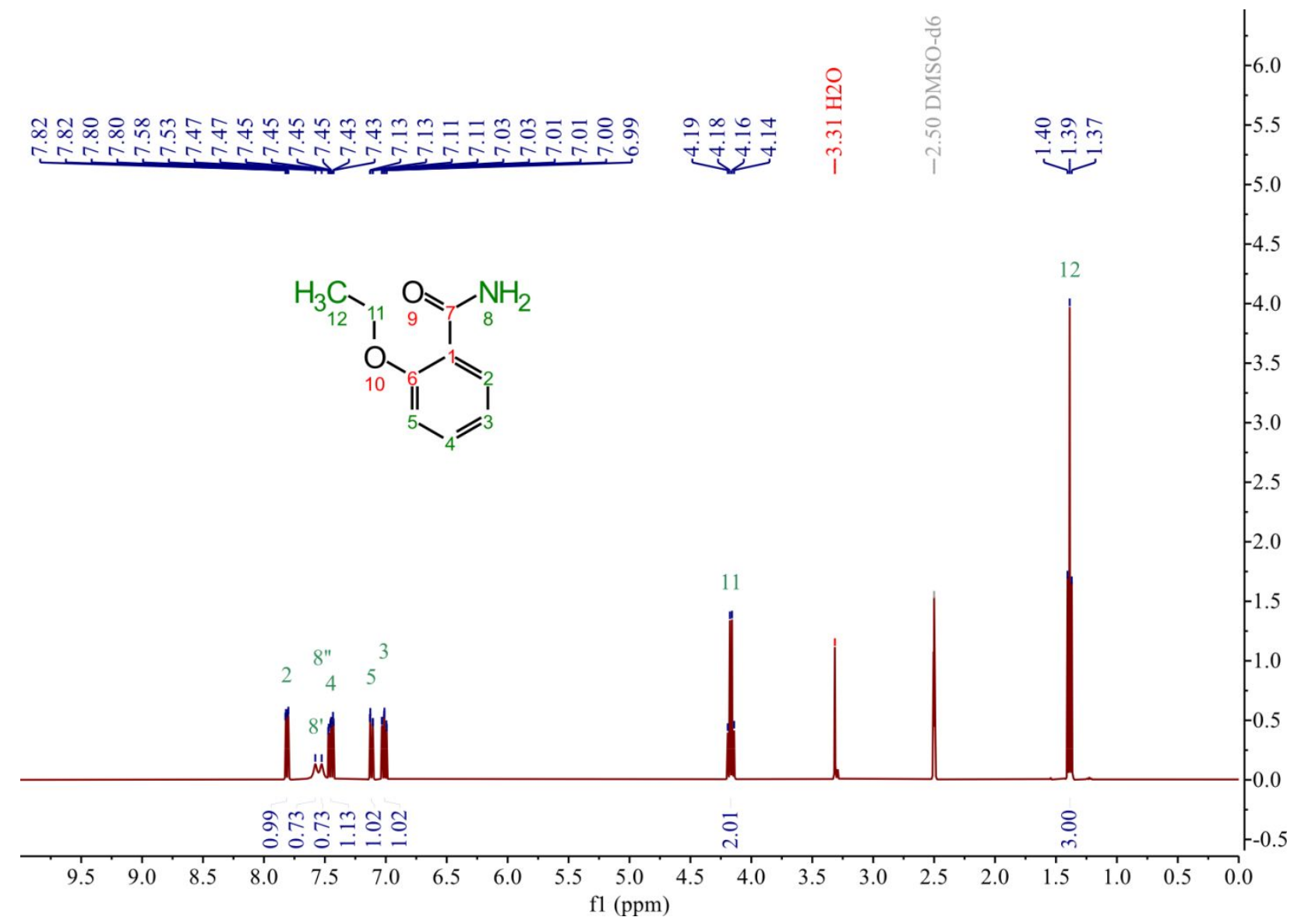

Figure S5. ${ }^{1} \mathrm{H}$ NMR of $2 \mathrm{~EB}$ after crystallisation from a 6:1 VODES with phenol. All peaks can be assigned to $2 \mathrm{~EB}$ and are correctly integrated. There is no proton peak from phenol present (c.a. $9.28 \mathrm{ppm}$ in DMSO- $\mathrm{d}_{6}$ ), indicating an absence of residual phenol in the product. 


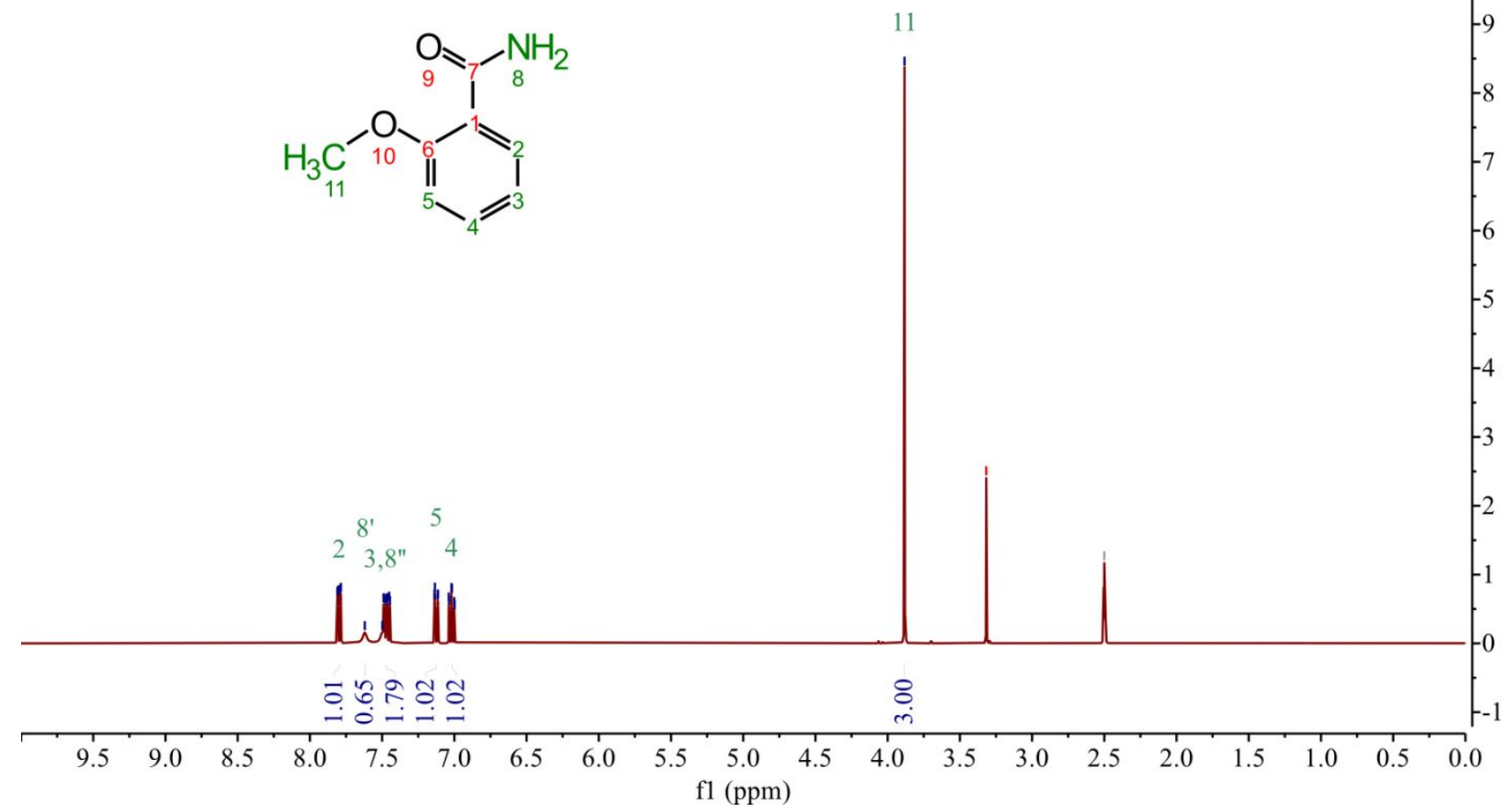

Figure S6. ${ }^{1} \mathrm{H}$ NMR of $2 \mathrm{MB}$ after crystallisation from a 6:1 VODES with phenol. All peaks can be assigned to $2 \mathrm{MB}$ and are correctly integrated. There is no proton peak from phenol present (c.a. $9.28 \mathrm{ppm}$ in DMSO- $\mathrm{d}_{6}$ ), indicating an absence of residual phenol in the product. 


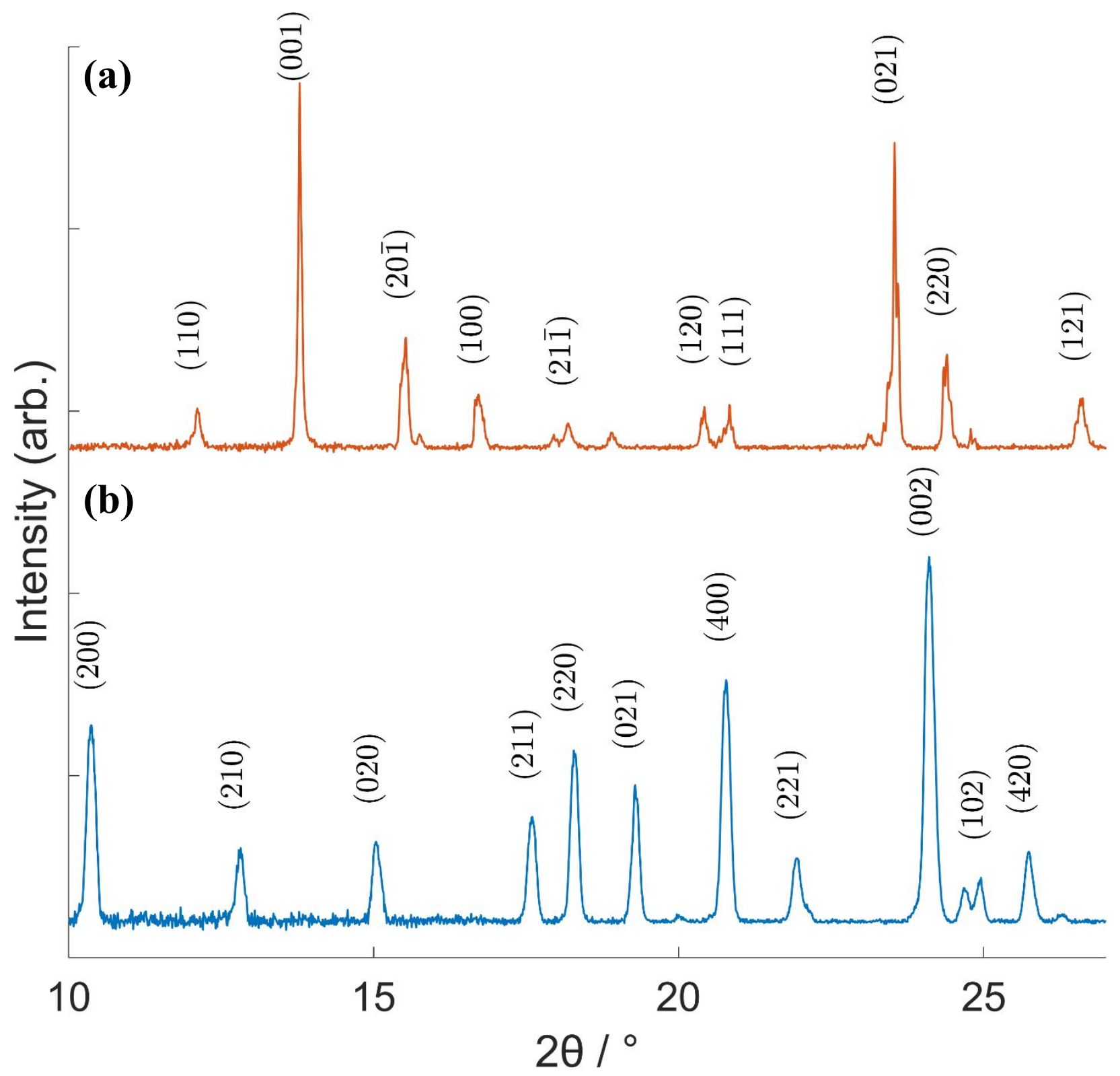

Figure S7 Powder X-ray diffraction patterns of (a) paracetamol form I (deep eutectic ratios 4:1

- 6:1) and (b) paracetamol form II (deep eutectic ratios 7:1 - 9:1). All peaks can be indexed to their respective polymorph (form I CCDC Identifier - HXACAN01; form II CCDC Identifier HXACAN). 

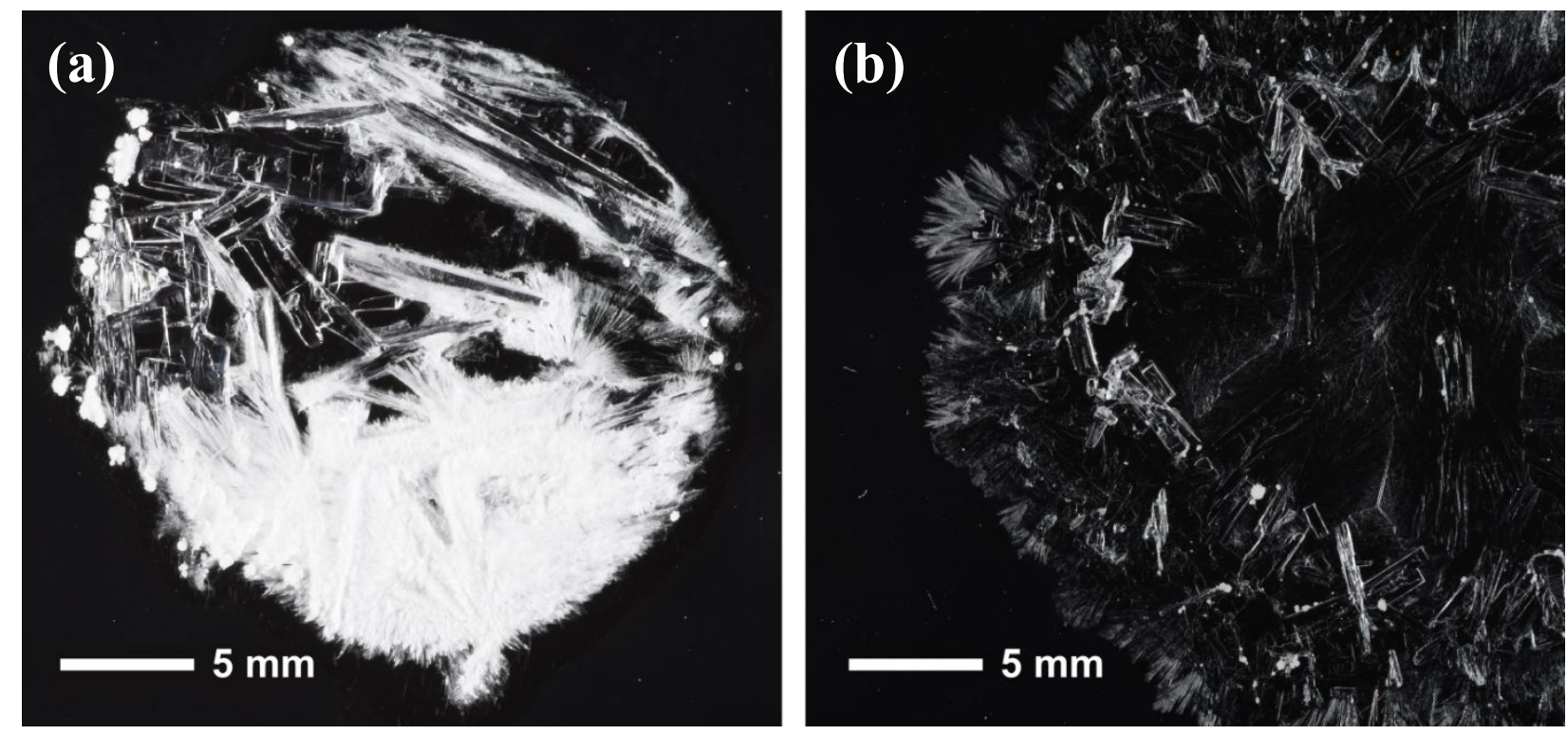

Figure S8. VODES crystallisation of benzamide showing (a) both form I (bottom, opaque needles) and form III (top, clear plates) and (b) form III exclusively. 

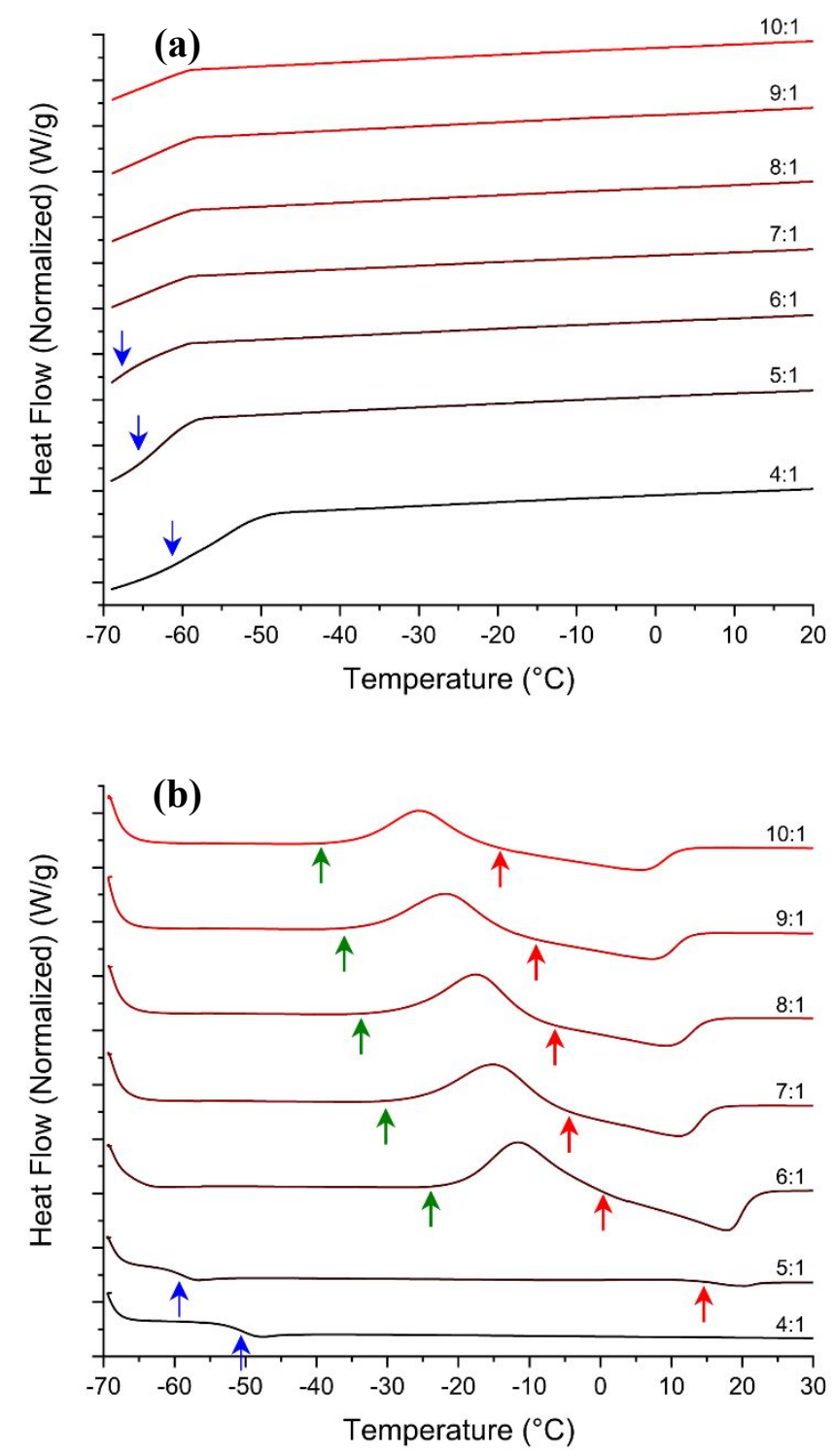

Figure S9. Thermal behaviour of paracetamol as a VODES with phenol. Thermograms of each VODES ratio for (a) cooling and (b) warming, truncated to remove featureless data. Coloured arrows of blue green and red indicate the positions of a $T_{g}$, a crystallisation event and a melt event, respectively. 

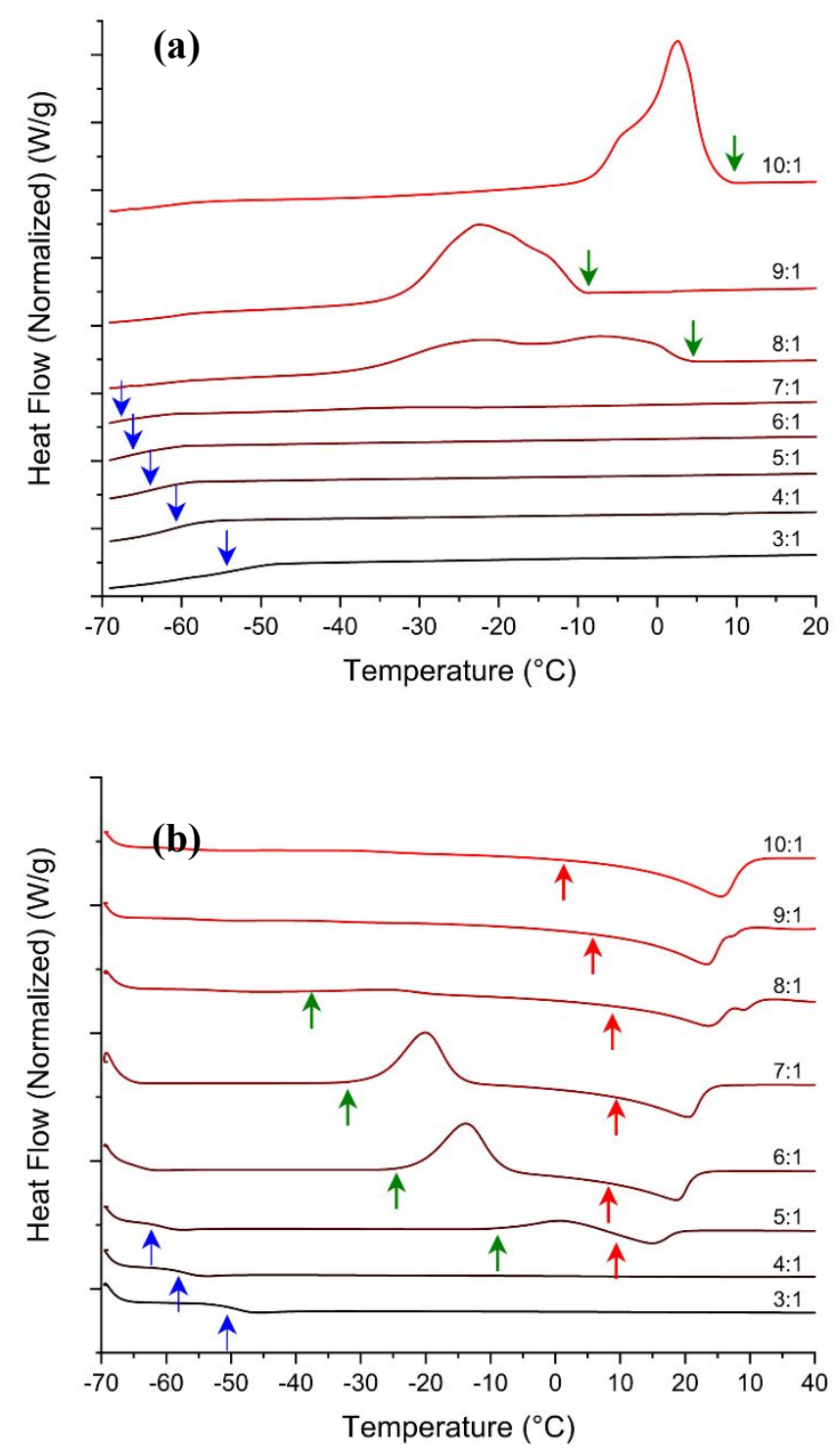

Figure S10. Thermal behaviour of metacetamol as a VODES with phenol. Thermograms of each VODES ratio for (a) cooling and (b) warming, truncated to remove featureless data. Coloured arrows of blue green and red indicate the positions of a $T_{g}$, a crystallisation event and a melt event, respectively. 

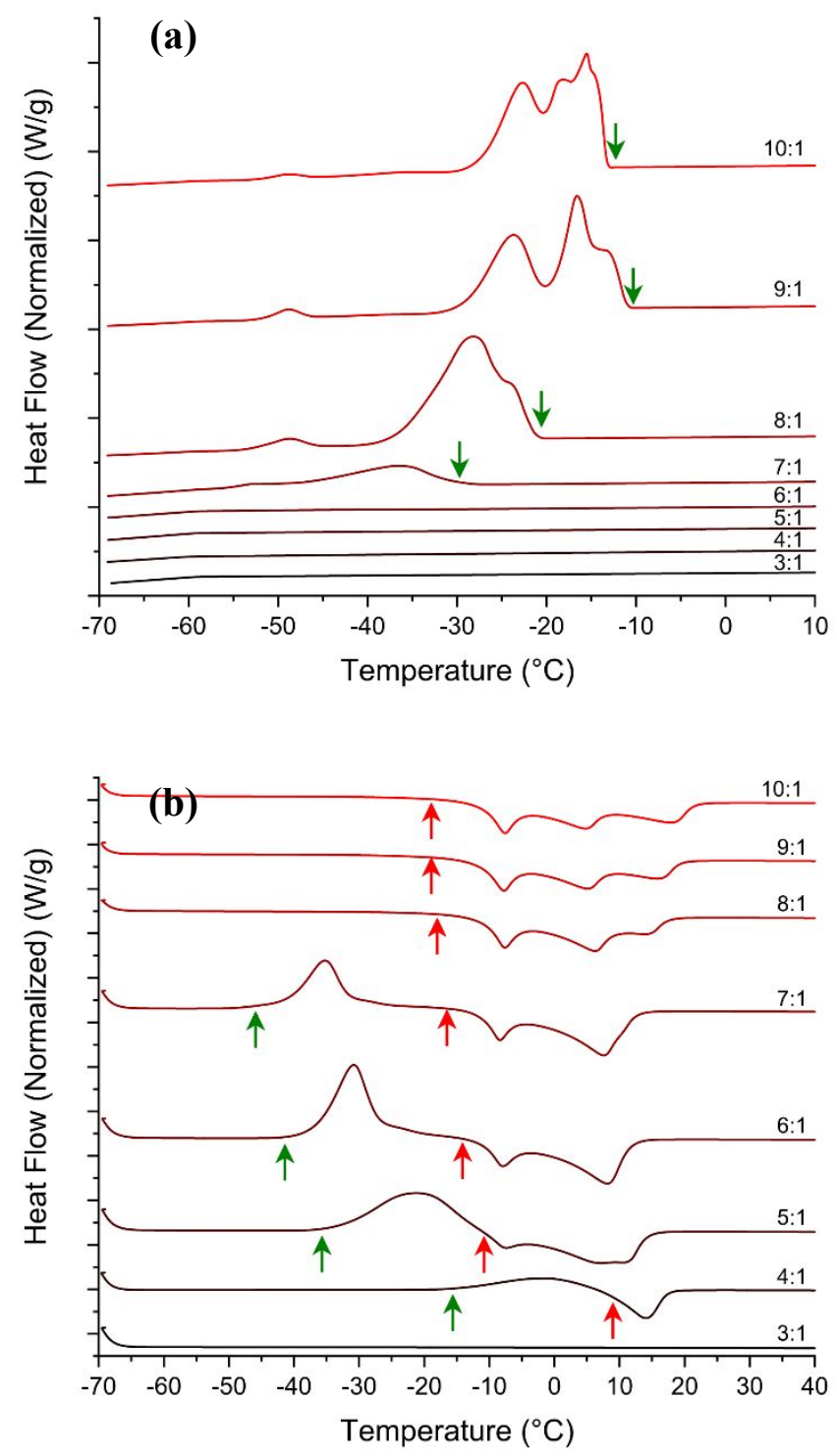

Figure S11. Thermal behaviour of benzamide as a VODES with phenol. Thermograms of each VODES ratio for (a) cooling and (b) warming, truncated to remove featureless data. Coloured arrows of blue green and red indicate the positions of a $T_{g}$, a crystallisation event and a melt event, respectively. 

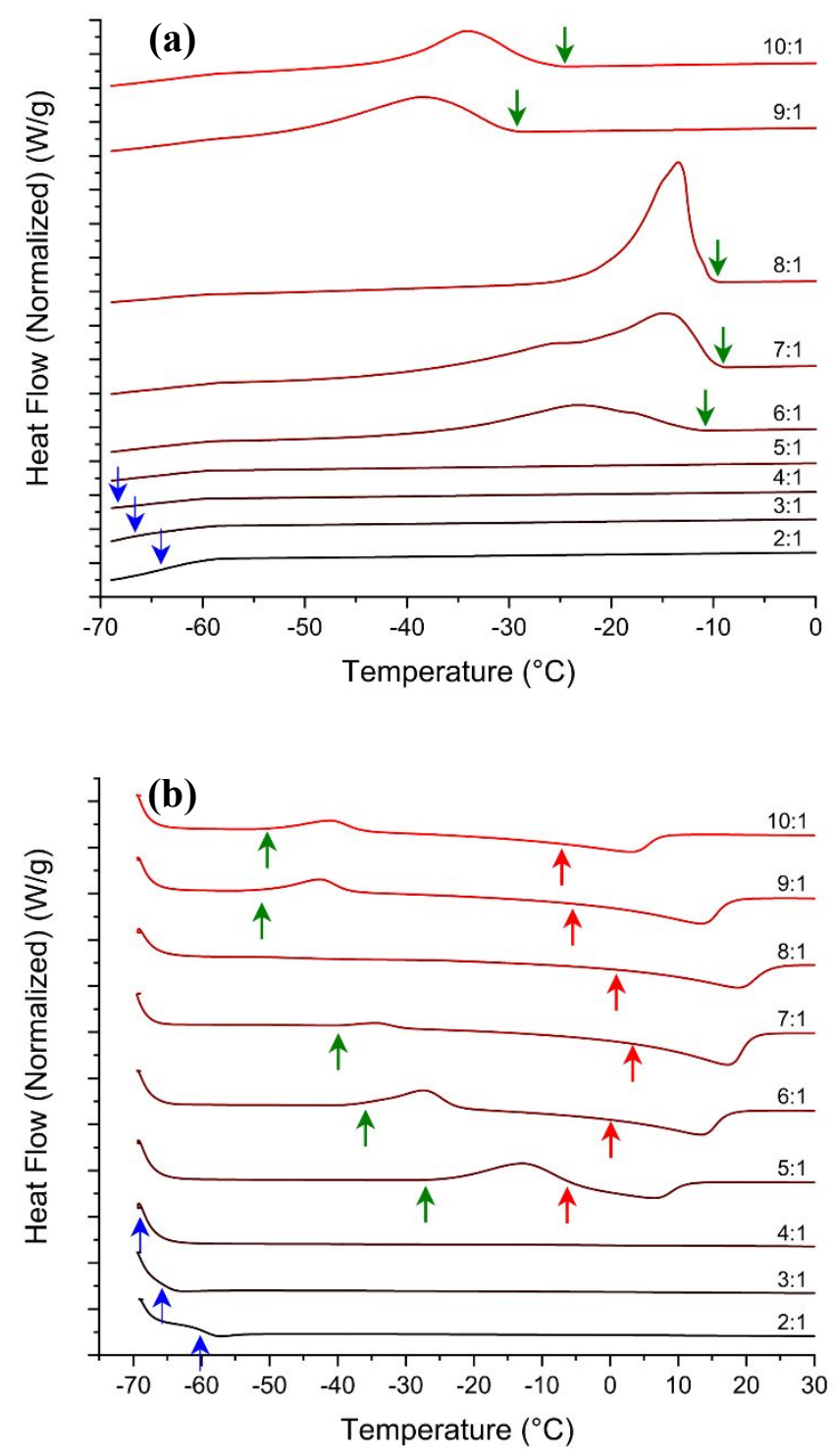

Figure S12. Thermal behaviour of $2 \mathrm{MB}$ as a VODES with phenol. Thermograms of each VODES ratio for (a) cooling and (b) warming, truncated to remove featureless data. Coloured arrows of blue green and red indicate the positions of a $T_{g}$, a crystallisation event and a melt event, respectively. 

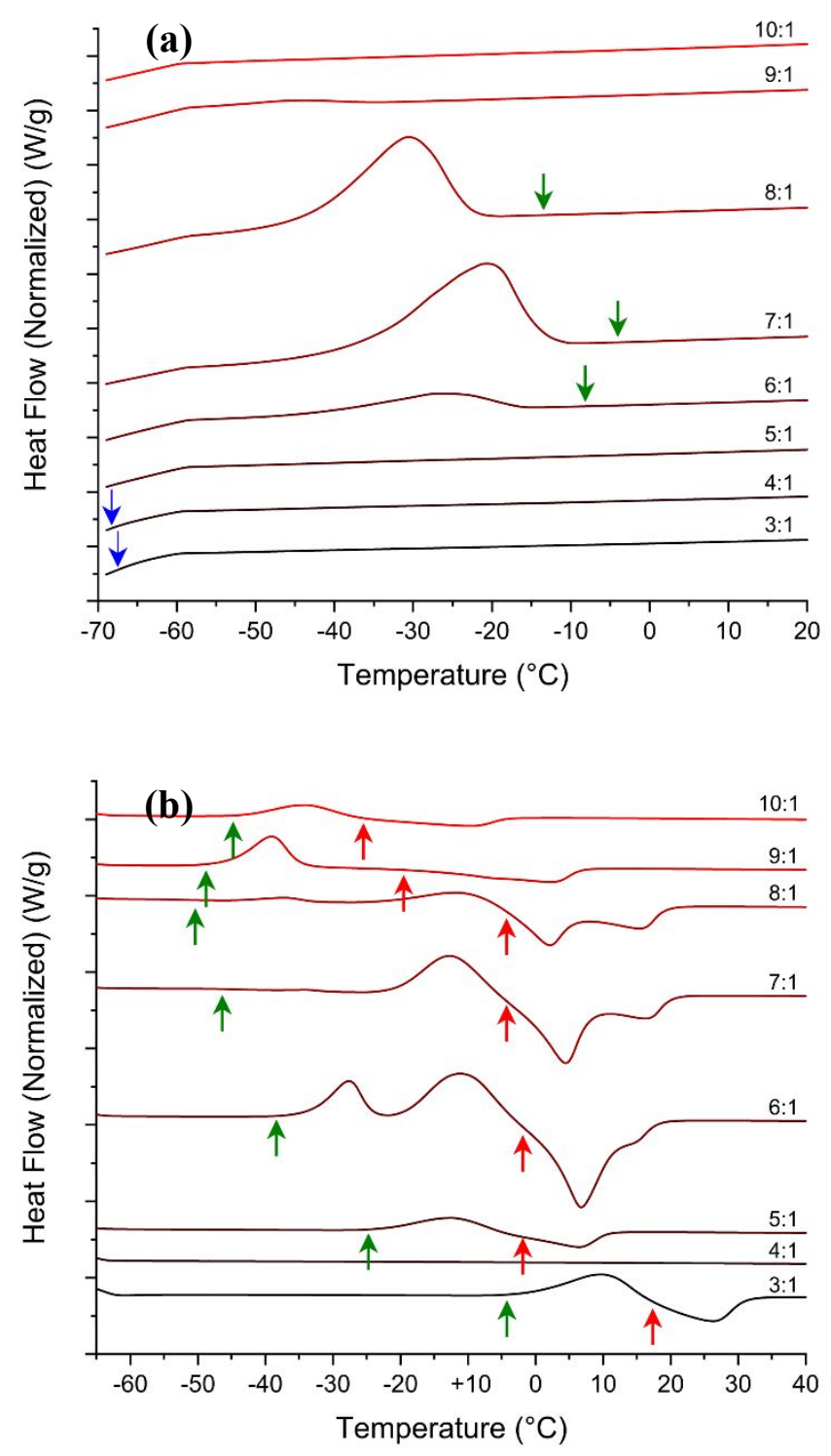

Figure S13. Thermal behaviour of 2EB as a VODES with phenol. Thermograms of each VODES ratio for (a) cooling and (b) warming, truncated to remove featureless data. Coloured arrows of blue green and red indicate the positions of a $T_{g}$, a crystallisation event and a melt event, respectively. 


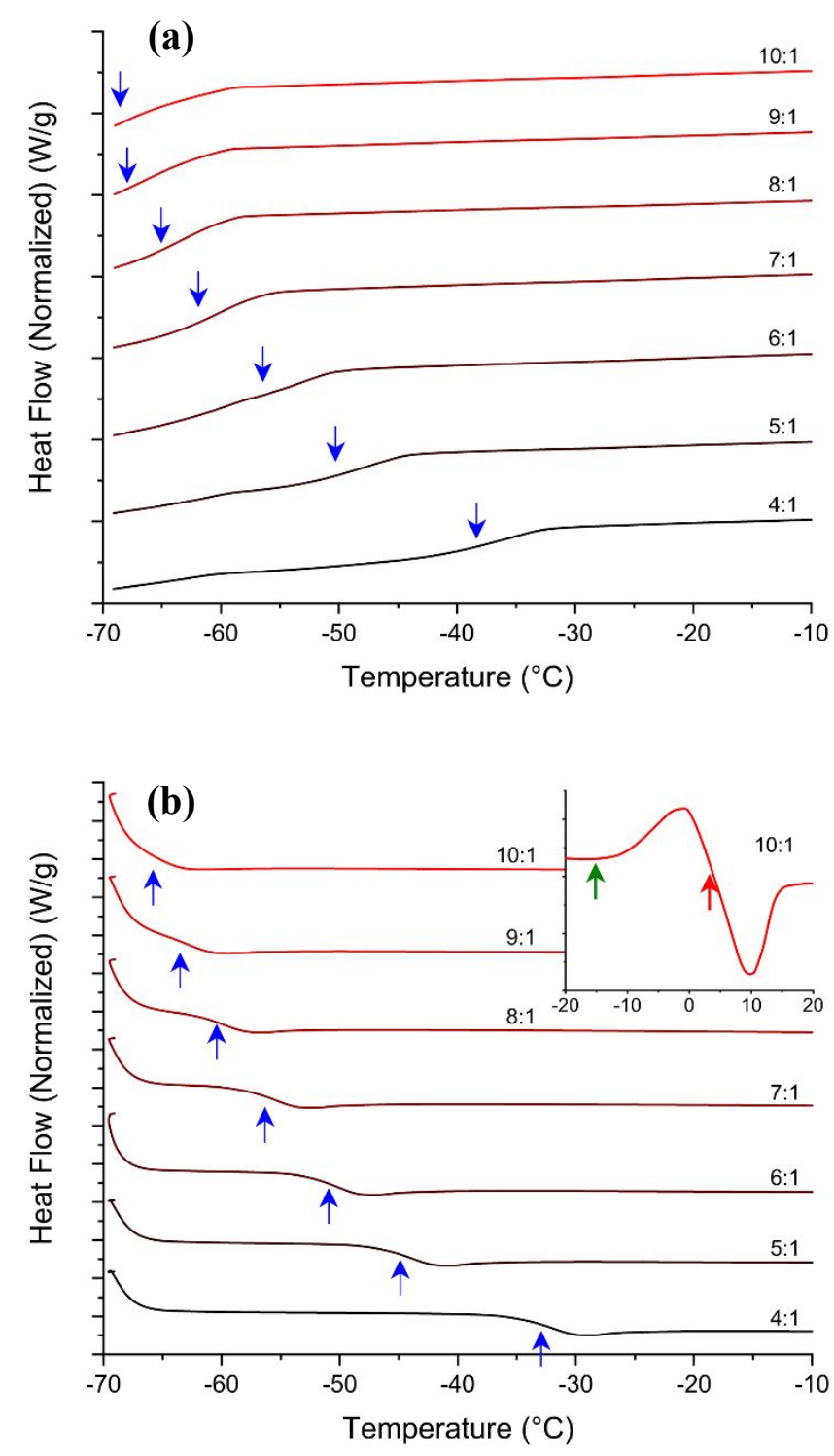

Figure S14. Thermal behaviour of carbamazepine as a VODES with phenol. Thermograms of each VODES ratio for (a) cooling and (b) warming, truncated to remove featureless data. Coloured arrows of blue green and red indicate the positions of a $T_{g}$, a crystallisation event and a melt event, respectively. 
(a)
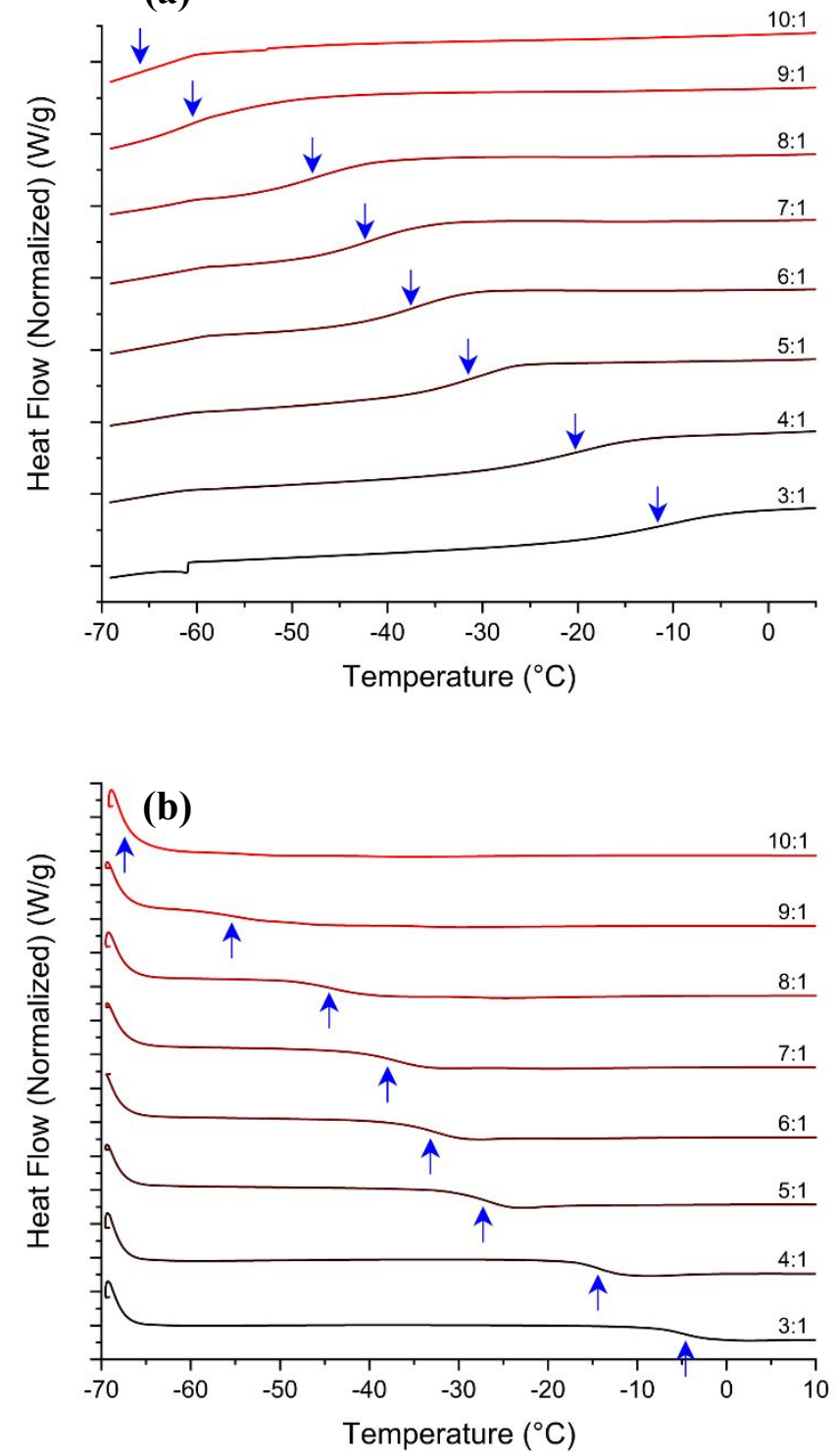

Figure S15. Thermal behaviour of verapamil hydrochloride as a VODES with phenol.

Thermograms of each VODES ratio for (a) cooling and (b) warming, truncated to remove featureless data. Coloured arrows of blue green and red indicate the positions of a $T_{g}$, $a$ crystallisation event and a melt event, respectively. 

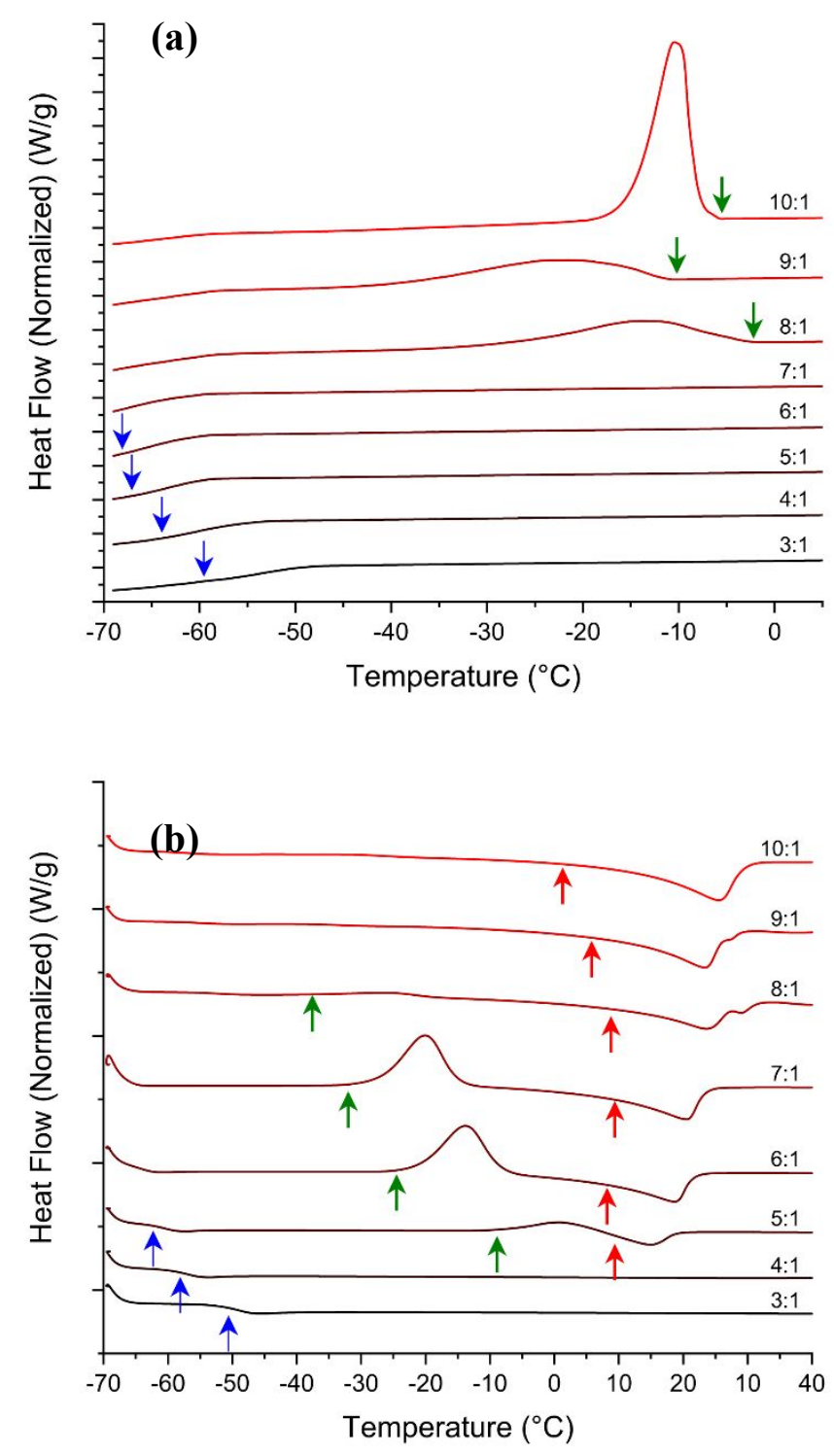

Figure S16. Thermal behaviour of metaxalone as a VODES with phenol. Thermograms of each VODES ratio for (a) cooling and (b) warming, truncated to remove featureless data. Coloured arrows of blue green and red indicate the positions of a $T_{g}$, a crystallisation event and a melt event, respectively. 


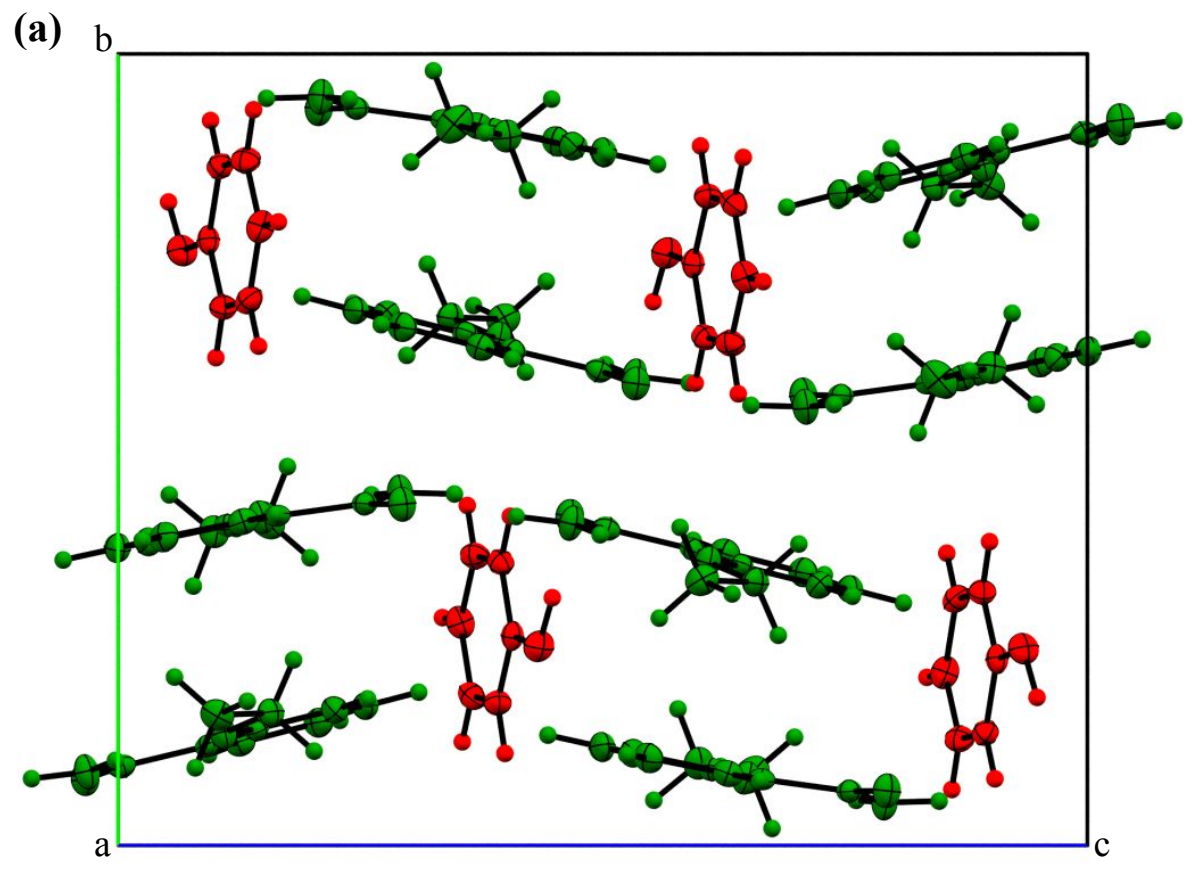

(b)

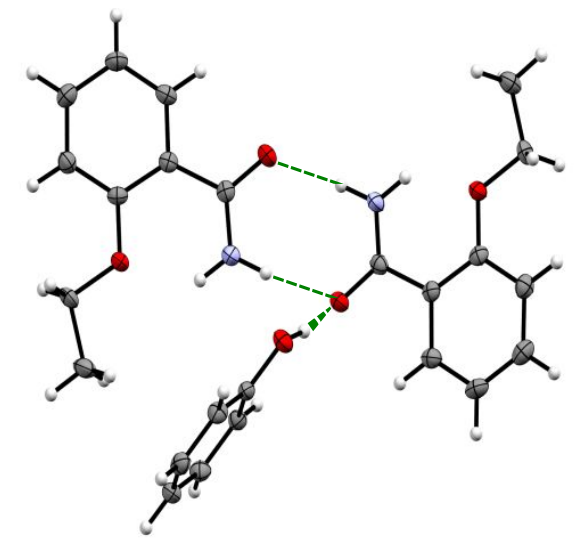

Figure S17. Crystal structure of a co-crystal of 2-ethoxybenzamide and phenol at a 1:2 ratio.

(CCDC deposit number 1879336). 
(a)

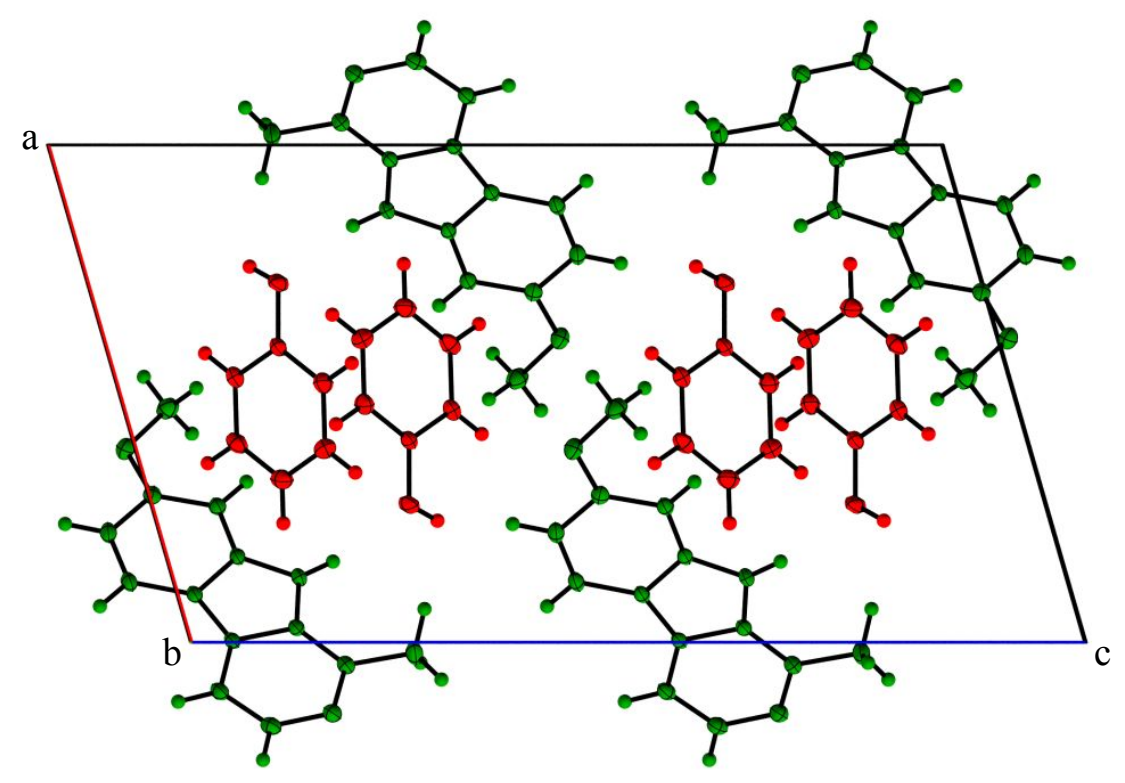

(b)

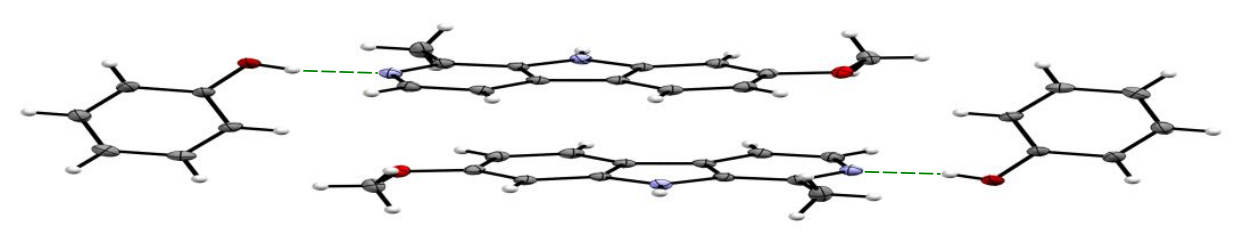

Figure S18. Crystal structure of a co-crystal of harmine and phenol at a 1:1 ratio. (CCDC deposit number 1879689). 


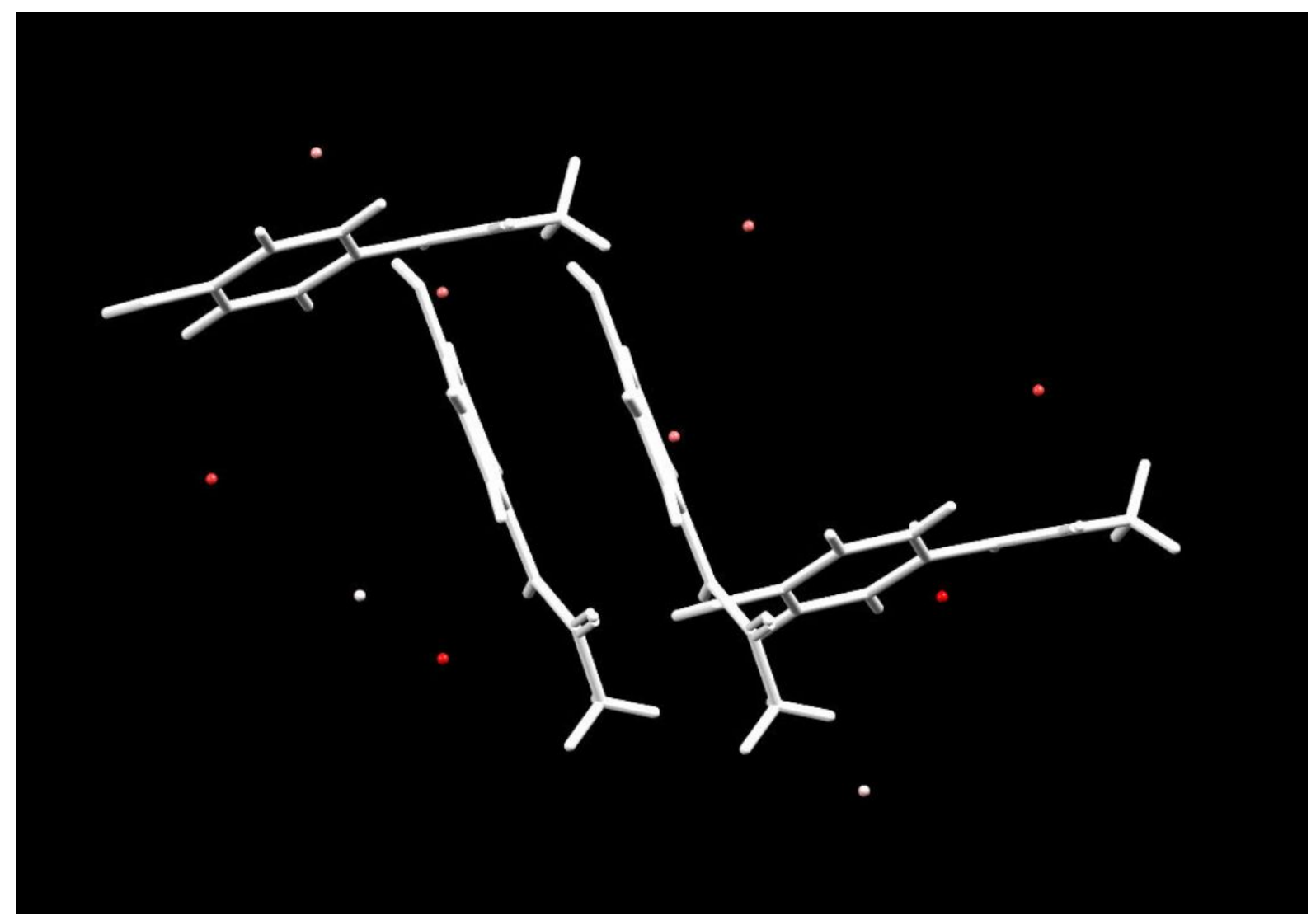

Figure S19. The results from 10000 optimisations of phenol with PAP form I using ORIENT.

Dots indicate the position that the oxygen of the phenol will adopt, the colour representing the

relative energy with red being the most stable and white being least stable. The 10000 optimisations indicate 11 potential positions. 


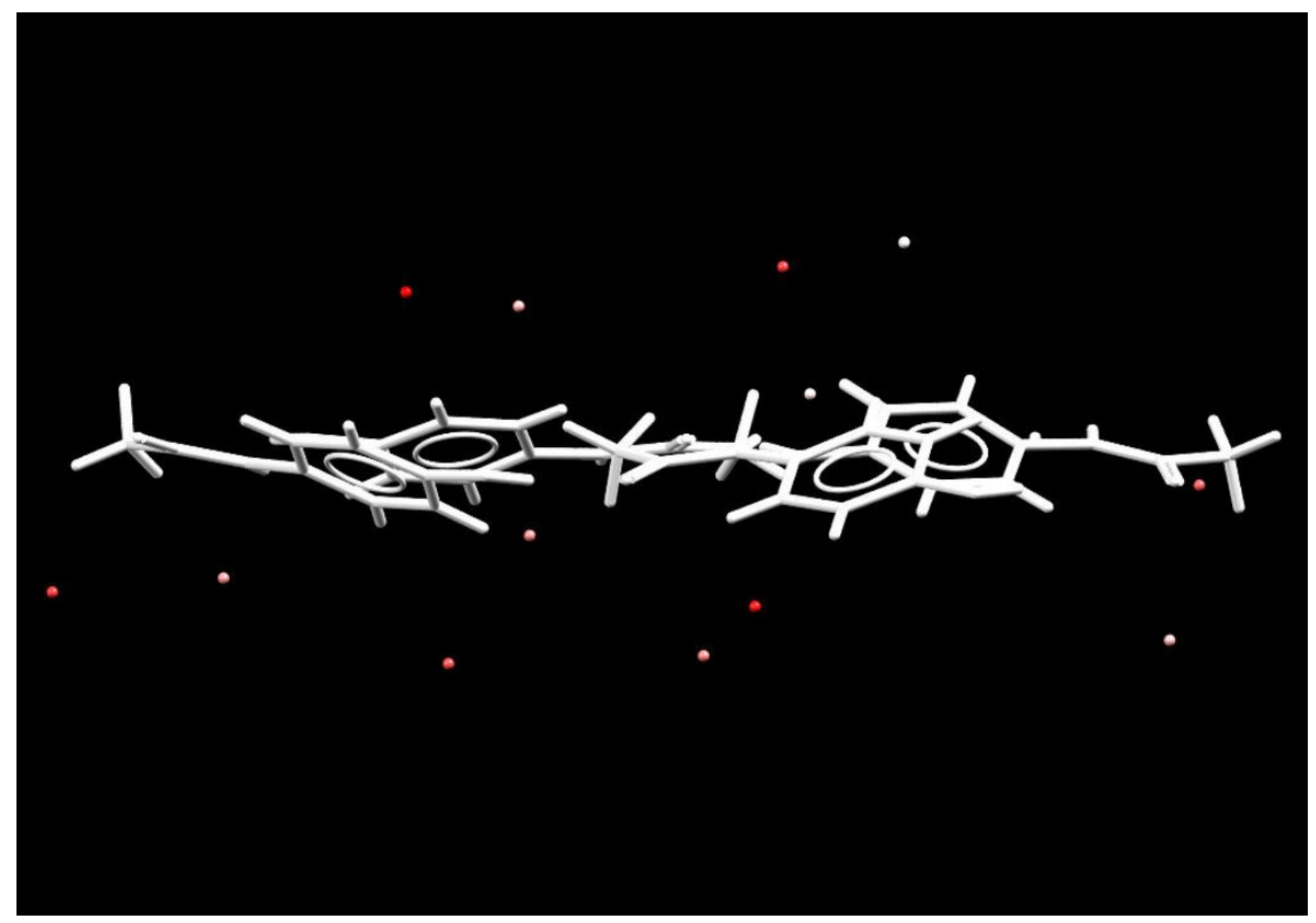

Figure S20. The results from 10000 optimisations of phenol with PAP form II using ORIENT.

Dots indicate the position that the oxygen of the phenol will adopt, the colour representing the relative energy with red being the most stable and white being least stable. The 10000 optimisations indicate 14 potential positions. 


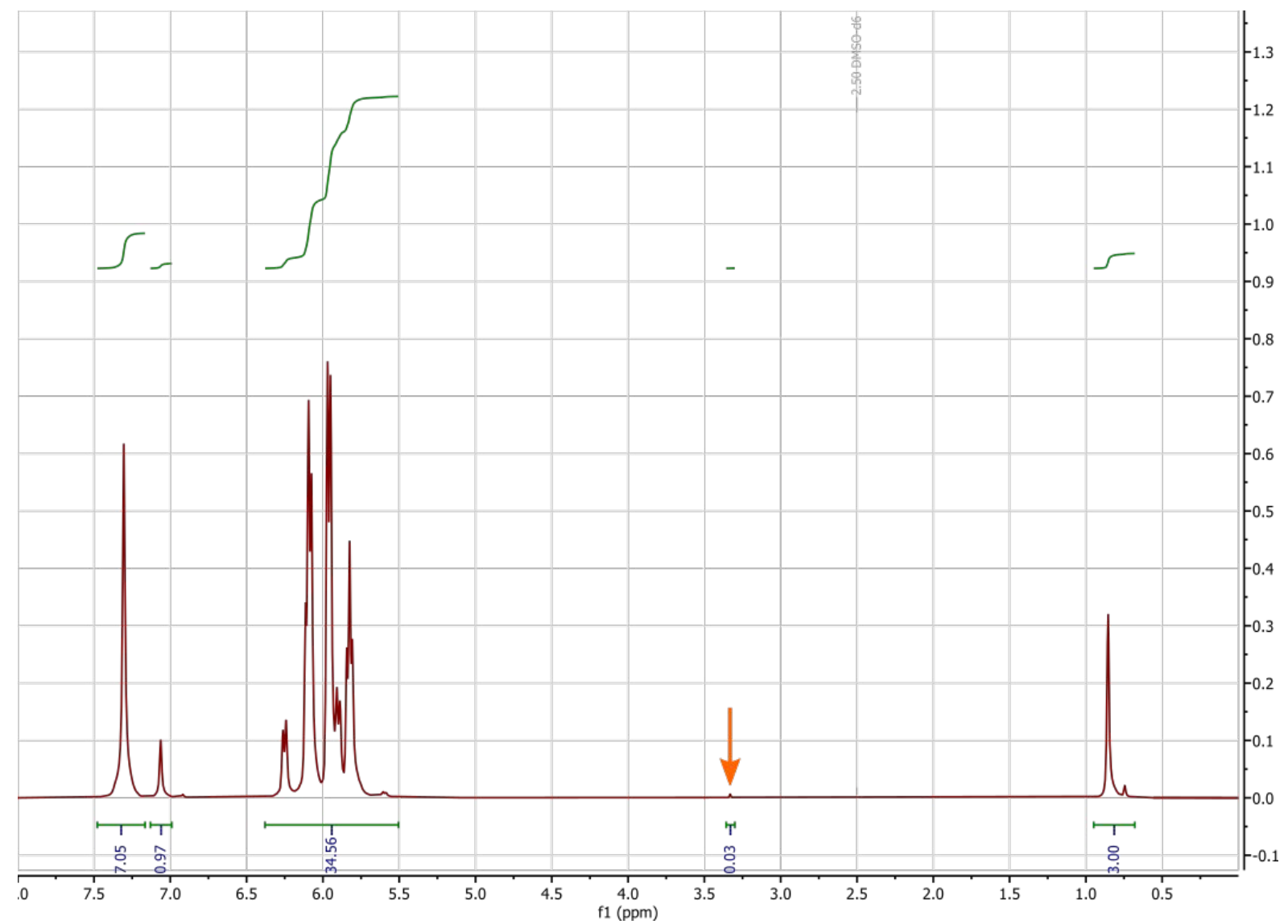

Figure S21. $\mathrm{H}^{+}$NMR of a native Phenol:PAP VODES with ratio 6:1 to assess water content.

Solvent lock was achieved by sealing DMSO-d6 in a glass capillary and inserting it into the NMR tube. The orange arrow indicates the water peak. Using integration of the PAP methyl peak, the ratio can be calculated as 70:420:1, PAP:Phenol:water. 